\title{
RENTABILIDAD, EVOLUCIÓN PATRIMONIAL Y DIVERSIFICACIÓN EN TRES GRANDES COMPAÑÍAS ARGENTINAS, 1926-1955*
}

\author{
PROFITABILITY, DIVERSIFICATION, \\ AND NET WORTH IN THREE ARGENTINE \\ BIG COMPANIES, 1926-1955
}

\author{
E. Martín Cuesta \\ Universidad de Buenos Aires, Buenos Aires, Argentina, martincuesta@conicet.gov.ar \\ Carlos Newland \\ Instituto Universitario ESEADE, Buenos Aires, Argentina, newland@eseade.edu.ar
}

\begin{abstract}
Resumen. Este trabajo presenta un análisis comparativo de tres grandes empresas argentinas (Bunge y Born; Garovaglio y Zorraquín, y Mercado Central de Frutos) entre 1926 y 1955. Se detalla la evolución del patrimonio y utilidad de estas firmas, los que se relacionan con las condiciones de negocios y macroeconómicas. Se considera que estos indicadores reflejan adecuadamente el desempeño empresarial, así como los resultados de sus diversas estrategias. Utilizando como fuentes las memorias y balances de estas organizaciones, se aborda la problemática de la diversificación y su relación con la rentabilidad.
\end{abstract}

Palabras clave: historia de empresas; historia argentina; Mercado Central de Frutos; rentabilidad empresaria.

Abstract. This paper presents a comparative analysis of three large Argentine companies (Bunge \& Born, Garovaglio \& Zorraquín, and Mercado Central de Frutos) between 1926 and 1955. The evolution of equity and profits is described, and related to business and macroeconomic conditions. These indicators reflect the performance of the companies, and the results of different business strategies. Using as sources reports and balance sheets the relationship between diversification and profits is discussed.

Key words: business history; Argentine history; Mercado Central de Frutos; enterprises profits.

Fecha de recepción: 1 de junio de 2015. Fecha de aceptación: 14 de octubre de 2015.

* Agradecemos la colaboración en la consulta de fuentes del personal de la Biblioteca y Archivo de la Bolsa de Comercio de Buenos Aires y al de la Biblioteca Tornquist del Banco Central de la República Argentina. También los valiosos y sensatos comentarios de Alicia Saliva, Lionel Barabagallo y de los evaluadores anónimos de esta revista.

Am. Lat. Hist. Econ., mayo-agosto, 2016, pp. 204-228 | DOI: 10.18232/alhe.v23i2.713 


\section{INTRODUCCIÓN}

$\mathrm{E}$ ste trabajo analiza el desarrollo de tres firmas argentinas entre 1926 y 1955 a través de la evolución de sus utilidades y patrimonio. Estas empresas tuvieron su origen a finales del siglo XIX en la intermediación en el comercio exterior, actividad que continuaron desarrollando a lo largo del periodo. Una de ellas, Mercado Central de Frutos, mantuvo el mismo perfil en el tiempo; las otras dos, Garovaglio y Zorraquín, y Bunge y Born se transformaron en grupos económicos ${ }^{1}$ al diversificar sus inversiones. Las firmas poseían desde las primeras décadas del siglo XX una magnitud que las colocaba entre las más importantes del país. En sus respectivas actividades contaban con una situación dominante en el comercio de lana, azúcar y granos, aunque en todos los casos sufrieron competencia de otras empresas. En un ranking por capital integrado de casi 1200 sociedades anónimas en funcionamiento en 1928 las tres compañías se encontraban entre las 100 más grandes, destacando Bunge y Born por ocupar el puesto $24 .^{2}$ Dimensión destacada, origen similar pero estrategias distintas en cuanto a diversificación, son aspectos que las hacen interesantes y justifican el ejercicio comparativo. Newland $(2012,2015)$ y Cuesta $(2013,2014)$ han estudiado con anterioridad a Mercado Central de Frutos y Garovaglio y Zorraquín individualmente. Nueva información contable obtenida de Bunge y Born, unida a los estudios clásicos de Green y Laurent (1988), Schvarzer (1989), y el más reciente Ceva (2010), sobre esta organización, hacen posible el contraste aquí presentado. ${ }^{3}$

Es muy relevante para Argentina la temática de las estrategias de diversificación o cambio de rumbo de las empresas entre 1926 y 1955, puesto que tanto la economía mundial como la local sufrieron agudos cambios. Desde una situación inicial de integración al comercio mundial y a un patrón de especialización internacional de producción, se pasó gradualmente a un escenario más autárquico. Esto implicó para la mayor parte de los países mejores condiciones para las actividades industriales, respecto de aquellas vinculadas con el sector primario y su comercialización. En

${ }^{1}$ En este trabajo se utiliza indistintamente el término holding o grupo empresarial en referencia a Garovaglio y Zorraquín y a Bunge y Born. Holding es un término algo más restrictivo, ya que implica la tenencia de un paquete accionario que permite el control de varias empresas, lo que fue el caso en relación con los emprendimientos industriales. Grupo empresarial es un término más genérico que también se aplica a estas entidades, ya que incorpora actividades económicas realizadas directamente por la entidad propietaria, en este caso la comercialización de azúcar o granos.

${ }^{2}$ El listado de las sociedades anónimas (1 de febrero de 1929). El Avisador Mercantil.

${ }^{3}$ Para el grupo mayor, Bunge y Born, la información es más escasa, producto del celo con que la empresa ha limitado la difusión de su información interna (además de que al no cotizar en bolsa no tuvo la obligación de publicar memorias y balances). 
Argentina el cambio fue muy dramático a medida que avanzaba tanto un marco altamente proteccionista con políticas crediticias y cambiarias favorables al desarrollo manufacturero. Como se verá a continuación, las firmas previeron y reaccionaron, en mayor o menor grado, ante estas alteraciones en sus entornos. Por ello las empresas argentinas se presentan como un campo fértil para testear el enfoque de contingencia del liderazgo, ya que el éxito de estas depende en buena medida de las habilidades de sus conductores para adoptar las transformaciones ante los cambios en los contextos en que actúan. Esta adaptación puede tomar diversos formatos: en cuanto a diversificación puede concretarse en emprendimientos relacionados o no relacionados. En el primer caso la ventaja está en las sinergias presentes en las diversas actividades encaradas. En el segundo el objetivo es minimizar riesgos al actuar en sectores muy distintos, aunque con la desventaja de una dispersión de esfuerzos. ${ }^{4}$ Recientemente Barbero y Lluch (2015) luego de analizar un gran conjunto de firmas argentinas de origen familiar en el largo plazo, han concluido que la diversificación fue una de las estrategias adecuadas para tener éxito en un país con condiciones macroeconómicas e institucionales turbulentas. ${ }^{5}$

La historiografía de las empresas en Argentina es prolífica en investigaciones sobre firmas y conglomerados. ${ }^{6}$ Diversos estudios se han propuesto desentrañar las características y evolución de las empresas, junto con un análisis de desempeño y estrategias, y el impacto de redes. ${ }^{7}$ Por otra parte siempre ha estado en el horizonte el debate sobre las características del empresariado argentino planteado por Sábato (1991), quien los describe como actores que prefieren mantener fondos líquidos y diversificarse en pos de la maximización de utilidades y minimización del riesgo. Cabe mencionar que aun cuando la historiografía de empresas se encuentra en desarrollo constante, los estudios sobre beneficios y rentabilidad no son abundantes. ${ }^{8}$ Ello no ocurre únicamente en el caso argentino: un grupo de investigación fue formado para cubrir la misma vacancia en cuanto a la

${ }^{4}$ Una evaluación reciente de los beneficios y perjuicios que genera la diversificación se encuentra en Erdorf, Hartmann-Wendels, Heinrichs, Matz (2013). Sobre enfoques que analizan la adaptabilidad del management a contextos cambiantes (incluyendo la teoría del liderazgo contingente), véase Yukl y Mahsud (2010).

${ }^{5}$ Sobre la inestabilidad de las variables macroeconómicas argentinas a lo largo de su historia, véase Fanelli y Albrieu (2011).

${ }^{6}$ Para un estado de la cuestión sobre la historia de empresas en Argentina y Latinoamérica, véase Barbero (2006), Barbero y Raúl Jacob (2008) y Rougier (2013). También véase López (2006).

${ }^{7}$ Por ejemplo, véase el trabajo de Barbero (2000). Para estudios similares en México, véase Marichal y Cerutti (1997).

${ }^{8}$ Principalmente tres autores (Cuesta, Pineda y Lanciotti) han producido estudios que incorporan un análisis de rentabilidad y su relación con el patrimonio o capital: Cuesta $(2013,2014)$; Lanciotti (2011), Lanciotti y Bartolomé (2014); Pineda (2007). Estudios tempranos que incluyen 
historia empresarial del viejo continente, con el postulado de que la rentabilidad y el desempeño deberían estar en el centro de la disciplina. ${ }^{9}$ Un reciente panorama de la historia de la empresa en Latinoamérica aporta algunas características observadas en la región, tales como la variedad de los niveles de beneficios entre países ${ }^{10}$ y el efecto diferencial de la gestión del fundador, el tamaño y el hecho de cotizar en la bolsa (Fernández y Lluch, 2015). ${ }^{11}$

Con el propósito de evaluar las trayectorias y estrategias comparativas de las tres grandes empresas, en este artículo se analizan series largas de utilidades y patrimonio. A tal efecto, se ha contado con información diversa, como recuerdos personales, actas de directorio, memorias anuales, y especialmente balances. Los estados contables aportan gran cantidad de información continua y organizada, y tienen la ventaja de su disponibilidad, al constituir un insumo básico para la toma de decisiones en el interior de las empresas, y al tener que ser presentados ante organismos públicos y bolsas de comercio. Esto les otorga cierta credibilidad, aunque puede discutirse si son un reflejo fiel de la situación de una organización, puesto que la información contable podría ser alterada para ocultar información sensible, en cuanto al aspecto impositivo o de exposición. La cuestión fue tratada por Tafunell (2000, pp. 72-74) en un trabajo clásico sobre la rentabilidad de las empresas españolas en el largo plazo, en el que la propuesta del autor fue la siguiente: pese a la existencia de errores en las magnitudes, si los datos presentan cierta coherencia interna y correlación con tendencias de variables macro, pueden ser utilizadas con prudencia, con la advertencia de que las conclusiones derivadas tendrán un valor provisorio. Esto ha sido confirmado en un panorama sobre la evaluación del desempeño empresarial en perspectiva histórica. Por ello el análisis de la rentabilidad y longevidad de la firmas, junto con su capacidad adaptativa, ofrecen el

un análisis de rentabilidad son Guy (1988) y Gutiérrez y Korol (1988). También adopta esta perspectiva Newland (2015). Sobre el mercado de capitales véase Rougier (2012b).

${ }^{9}$ Véase http://www.lse.ac.uk/economicHistory/BHU/research/performanceEB.aspx Un primer intento del grupo de brindar un análisis comparativo europeo a lo largo del siglo $\mathrm{xx}$ destacó que hacia 1913 las firmas que ofrecían mayor rendimiento estaban en buena parte vinculadas al sector primario (como la minería). Para el año 2000 las empresas más rentables pasaron a ser aquellas vinculadas al sector servicios y a las telecomunicaciones. Algunos sectores mantuvieron sus ganancias en el lapso, como el petrolero, el químico y el bancario. Por otra parte las empresas pequeñas aumentaron su rentabilidad respecto a las más grandes en el tiempo. Véase Cassis y Brautaset (2003). El grupo no pudo cumplir su cometido al discontinuarse el Business History Unit de The London School of Economics a partir de 2015 (http://www.lse.ac.uk/economicHistory/BHU/Home.aspx).

${ }^{10}$ Elevadas en el caso de Perú, México y Colombia.

${ }^{11}$ Varios estudios han marcado que empresas que cotizan en la bolsa presentan una rentabilidad superior, por ejemplo en Chile. Véanse en especial Martínez, Stöhr, B. y Quiroga (2007) y Bonilla, Sepúlveda y Carvajal (2010). 
mejor medio para evaluar el éxito empresarial en el largo plazo. Aunque los balances contables y estados de resultados ofrecen una imagen parcial y a veces distorsionada, utilizados con cautela brindan probablemente el mejor indicador del desempeño posible (Gourvish, 2006, pp. 388-389).

La utilidad es aquí definida como la diferencia entre los ingresos y costos anuales, antes de la aplicación de impuestos. En los costos se incluyen los salarios abonados, las cargas financieras y la depreciación de los activos. El patrimonio neto es el valor del capital aportado por los propietarios, más las reservas acumuladas de diverso tipo (que normalmente tienden a capitalizarse con el tiempo). La rentabilidad es el cociente de ambas magnitudes y puede interpretarse como la suma de una compensación al capital aportado por los propietarios, junto con una retribución a la gestión. El monto y evolución del patrimonio neto refleja si la empresa se encuentra en crecimiento o retracción: estas alteraciones sin duda dependen tanto de los beneficios percibidos, como de las expectativas futuras. Las magnitudes del patrimonio de las empresas analizadas presentan el problema de sufrir distorsiones con la aparición de la inflación a mediados de la década de 1940, un fenómeno que persistió a lo largo del lapso analizado. Puesto que una parte del activo, aquel correspondiente a terrenos, inmuebles y equipos, no se ajustaba con los cambios de precios, se fue generando en los registros contables una pérdida de valor, defecto que sólo fue corregido por la primera ley de revalúo contable de 1960. Para intentar eliminar la distorsión se ha vuelto a calcular el patrimonio neto de las firmas entre 1944 y $1961 .{ }^{12}$ Los valores de los años intermedios se estimaron mediante una interpolación geométrica. Un ajuste de este tipo es razonable para un rubro como el patrimonio que normalmente crece de manera progresiva, sin saltos demasiado abruptos. Otra magnitud que puede haber sido afectada por la inflación es la amortización, ya que la depreciación se realizaba según los valores históricos de adquisición. Sin embargo, un análisis de las cuentas de resultados de muchas empresas de la época indica que no parece existir una caída constante en la magnitud de la depreciación aplicada sobre las ganancias. La razón parece ser que las empresas aceleraban por motivos impositivos la imputación de las amortizaciones de sus equipos e instalaciones, lo que hizo que sus efectos sobre las ganancias fueran menos afectados por los cambios de los precios. ${ }^{13}$

La periodización propuesta, 1926-1932, 1933-1941, 1942-1948 y 19491955 se basa en la observación de que en estos periodos las empresas

\footnotetext{
${ }^{12}$ Puesto que el revalúo contable fue un proceso iniciado en 1960 y completado por las empresas en 1961.

${ }^{13}$ Según la opinión de Petrei (1973, pp. 383-384), quien analizó con detalle balances de cientos de empresas del periodo.
} 
presentan tendencias en sus rentabilidades relativamente similares. Debe señalarse que puesto que las fuentes son los balances contables, el año indicado para cada caso es el del mes de su cierre. Si se observa la evolución del producto bruto surge una periodización similar, con una sola diferencia notable: los efectos de la gran depresión se hacen sentir ya en 1930, y no en 1933. ${ }^{14}$ Es decir, las tres empresas analizadas comenzaron a sentir los efectos de la crisis un par de años después de que fuera afectada la actividad económica general. La explicación más plausible es que mientras que el valor de los productos comerciados por estos grupos caía, la rentabilidad de sus actividades financieras (en el caso de Bunge y Born y Garovaglio y Zorraquín) aumentaba. ${ }^{15}$ El inicio del segundo momento de cambio, entre 1941 y 1942, obedece al impacto causado por los efectos de la intensificación de la segunda guerra mundial, tal como fuera observado por Federico Pinedo (Llach, 1984). El último corte, en 1948-1949, es el tomado habitualmente en la historiografía económica argentina dado el agotamiento del modelo del peronismo clásico, y el cambio de rumbo en algunas de sus políticas.

\section{LAS EMPRESAS Y SUS ORÍGENES}

Aunque las tres empresas analizadas se ocuparon de intermediar o facilitar el comercio exterior, presentan características heterogéneas por los productos comerciados, el origen de sus ejecutivos y el de los capitales que las financiaron. Bunge y Born se expandió en el último cuarto del siglo XIX dedicada a la intermediación de granos, liderada por el emprendedurismo de los belgas Ernesto Bunge y Jorge Born, y las oportunidades que ofrecía la integración con una empresa familiar con fines comerciales similares situada en Amberes. Durante el primer tercio del siglo XX el grupo creció rápidamente hasta controlar buena parte del comercio exterior de cereales argentino. Además de ocuparse de la intermediación, la firma fue un importante actor financiero canalizando fondos propios y de bancos hacia los productores, una actividad usual entre los consignatarios. De las tres empresas analizadas Bunge y Born fue la más grande: su patrimonio en 1926 cuadruplicaba al de Garovaglio y Zorraquín, y era 50\% mayor que el de Mercado Central de Frutos.

\footnotetext{
${ }^{14}$ La relación entre el desempeño general de la economía y el de las empresas parece claro, aunque los estudios de caso pueden mostrar que no guardan siempre la misma tendencia y magnitud. Por ejemplo, en la industria textil de Brasil, analizada por Haber (1992).

${ }^{15}$ En esos primeros años de la década hay un incremento de la tasa de interés y un mantenimiento de las ganancias de entidades bancarias y consignatarias en general.
} 
Garovaglio y Zorraquín también nació relacionado al comercio internacional. Francisco Garovaglio llegó de Italia en 1882 con la representación de productos de su país para su venta local, entre los que destacaría el vermú Cinzano, de gran demanda entre la población inmigrante de la península. El crecimiento de sus actividades comerciales hizo que hacia 1898 contratara como empleado a Federico (Pico) Zorraquín Machain, un joven que pertenecía a una familia acomodada de Concordia. El nacimiento formal de Garovaglio y Zorraquín puede datarse en 1914, cuando el italiano y el argentino se asociaron y crearon una firma con un capital de 1000000 de pesos. En 1926 la compañía se transformaría en Garovaglio y Zorraquín Comercial y Financiera Limitada. Para ese momento la firma había aumentado notablemente su dimensión al recibir un sinnúmero de productos importados y locales en consignación para su venta mayorista, incluyendo bebidas alcohólicas, arroz, yerba, conservas y madera. Pronto fue adquiriendo gran escala la comercialización de azúcar y alcohol producida por ingenios del norte argentino, mismos que la firma distribuía desde Buenos Aires. De manera similar a Bunge y Born, la compañía ofrecía adelantos de fondos a sus comitentes, préstamos hipotecarios y descuentos de documentos. Después de la muerte de Garovaglio en 1927 el control de la empresa pasó a Pico Zorraquín y luego, a mediados de la década de 1940, a su hijo Federico (Fred), ${ }^{16}$ quien permaneció en el máximo cargo ejecutivo hasta 1961.

Mercado Central de Frutos fue creado en 1887 por el argentino Eduardo Casey con el objetivo de ser un complejo nodo logístico de distribución, depósito y transporte de lana y cueros. Con financiamiento británico, construyó un gigantesco edificio a la vera del Riachuelo, conectado a vías camineras, férreas y fluviales. Casey trasfirió el control de la firma al comerciante y político argentino Belisario Hueyo en 1889. Su hijo Alberto Hueyo, un abogado vinculado a múltiples empresas y también a la política (fue ministro de Hacienda entre 1932 y 1933) heredaría su administración en 1912, permaneciendo en el cargo nada menos que hasta $1962 .{ }^{17}$ La actividad que desplegó el mercado fue notable, y unos años después de su inauguración su capacidad era superada por la demanda. Hacia 1909 pasaban por sus instalaciones dos tercios de la lana exportada por el país. En sus bodegas se guardaban los productos hasta que eran embarcados hacia plazas internacionales, como Bélgica, Francia y Alemania. Además de servir de depósito, la función del mercado fue reunir a compradores

${ }^{16}$ Formalmente en 1947, al fallecer Pico Zorraquín.

${ }^{17}$ Mercado Central de Frutos fue gestionado por Alberto Hueyo hasta su muerte en 1962. De allí en adelante la empresa fue administrada hasta su cierre, por Carlos Leloir y Carlos Gómez Álzaga. 
y vendedores. Allí los consignatarios de lana y cueros y otros productos acordaban las transacciones con representantes directos e indirectos de las industrias del exterior y, desde la década de 1920, con las firmas textiles locales.

Las empresas familiares parecen ser predominantes en Latinoamérica. ${ }^{18}$ Las tres organizaciones trabajadas aquí no se pueden enmarcar conjuntamente bajo esta etiqueta. Aunque la gestión de Mercado Central de Frutos estuvo durante todo el periodo a cargo de Alberto Hueyo, no era estrictamente una empresa familiar. Respondía más bien a los intereses de los accionistas, que en gran parte eran consignatarios, comercializadores o productores de lana y cueros. En el caso de Garovaglio y Zorraquín sí fue del clásico control familiar; la gestión y la propiedad aún están en manos de miembros de la familia Zorraquín. Bunge y Born era de alguna manera bicéfala, ya que la propiedad quedó eventualmente concentrada en dos familias distintas, Born y Hirsch, cuyos integrantes conformaban buena parte de su directorio y se alternaron en su presidencia.

\section{EL FIN DE LA BELLE ÉPOQUE (1926-1932)}

Para mediados de la década de 1920 las tres firmas analizadas presentaban una situación sólida, lograda sobre la base de su desempeño y altas utilidades. No eran una excepción, según Pineda (2007), las altas ganancias (de más de dos dígitos), característica de muchas empresas afectadas por el alto crecimiento macroeconómico argentino. Tanto Bunge y Born como Garovaglio y Zorraquín presentaron entre 1926 y 1932 beneficios anuales de 15 y $12 \%$, respectivamente, aunque el porcentaje para Mercado Central de Frutos fue de 7\% (véase cuadro 1). Las ganancias estaban sustentadas en el gran volumen de productos que exportaba e importaba Argentina: el negocio era claramente administrar este flujo, lo que las tres entidades hacían con eficiencia. En la memoria de los ejecutivos de Bunge y Born (Born, 2008) esa época sería recordada en el futuro como fabulosa. Los volúmenes de los granos que exportó la firma en esos años no tuvieron parangón. Quintuplicaron los embarques logrados en la década de 1930, fueron ocho veces los de la década de 1940 y casi 20 veces los de la década de 1950 (Green y Laurent, 1988, p. 203).

Pese a la holgada situación inicial en el sector servicios, Bunge y Born se destacó desde temprano por sus inversiones manufactureras, actividad que fue alentada por la existencia de tarifas aduaneras moderadas, pro-

${ }^{18}$ Sobre el peso relativo y la importancia de las empresas familiares en América Latina, véase Fernández y Lluch (2015). 
CUADRO 1. RENTABILIDAD (UTILIDADES/PATRIMONIO NETO)

DEL MERCADO CENTRAL DE FRUTOS, BUNGE Y BORN, Y GAROVAGLIO Y ZORRAQUÍN (PORCENTAJE)

\begin{tabular}{lccc}
\hline & Mercado Central de Frutos & Bunge y Born & Garovaglio y Zorraquín \\
$1926-1932$ & 7 & 15 & 12 \\
$1933-1941$ & 5 & 8 & 5 \\
$1942-1948$ & 8 & 15 & 12 \\
$1949-1955$ & 6 & 11 & 11 \\
\hline
\end{tabular}

Fuentes: elaboración propia a partir de Memorias y Balances del Mercado Central de Frutos; Bunge y Born, y Garovaglio y Zorraquín, años 1926 a 1955.

porcionalmente más elevadas para algunos productos terminados como la vestimenta. A principios del siglo XX la empresa ya poseía una pequeña fábrica de envases y otra de bolsas arpilleras (beneficiada esta última por la prohibición de su importación). En 1902 fundaría su empresa industrial de mayor dimensión, Molinos Río de la Plata, un establecimiento harinero y luego productor de aceite y alimentos. En 1924 Bunge y Born instaló una planta desmotadora, que procesaba el algodón que comerciaba, y en 1926 creaba la textil Grafa para elaborar telas con esa materia prima. En 1925 se constituía la fábrica de pinturas Alba que utilizaría como insumo el aceite obtenido de las semillas de algodón. Para el fin de la década de 1920 Bunge y Born presentaba las características de su identidad futura: un holding tanto dedicado al comercio exterior como a una variedad de actividades industriales. En esta diversificación temprana tuvo un papel central su máximo ejecutivo Alfredo Hirsch (presidente del Directorio entre 1928 y 1956), un judío alemán que había llegado de Europa con experiencia empresarial y que se sumó al grupo en 1897. Hirsch era un empresario emprendedor de carácter optimista, meticuloso y planificador, que aplicaba modernas técnicas gerenciales en la administración. ${ }^{19}$ Con capacidad prospectiva, ya desde temprano consideró que el futuro del grupo estaba en las actividades industriales (Schvarzer, 1989, p. 7). Las empresas de Bunge y Born fueron un caso de diversificación relacionada: todas las entidades de alguna manera estaban vinculadas con los productos agropecuarios comerciados por el holding: los alimentos y harina con los cereales, y los textiles y pinturas con el algodón. Por otra parte, las bolsas arpilleras se utilizaban para trasportar

${ }^{19}$ Existe escasa información sobre el pensamiento de Hirsh. Sobre el tema puede consultarse el capítulo sobre Bunge y Born en Azzi y Titto (2008). 
los productos agropecuarios que intermediaba y los envases metálicos eran los contenedores de sus productos industriales. ${ }^{20}$

Durante los años veinte Mercado Central de Frutos tuvo un desempeño positivo, sin modificar su actividad como depósito e intermediario en la comercialización al exterior de diversos productos. El aumento de la producción lanera local y los altos precios impactaron favorablemente en la firma: niveles de utilidades razonables se mantuvieron estables hasta iniciada la década de 1930. Sin embargo, ya se notaba que no era la firma dinámica de principios de siglo, al quedar algo relegada por su localización (véase gráfica 1). La migración de los lanares a la Patagonia o a zonas que contaban con otros centros de comercialización más cercanos, como el Mercado Victoria de Bahía Blanca, redujeron su actividad. Por su parte, Garovaglio y Zorraquín -en los años finales de la década de 1920- continuó su crecimiento basado en la consignación de productos importados y en la distribución de azúcar proveniente de ingenios del norte argentino. El negocio era rentable, basado en una gestión eficaz y en la demanda creciente de productos para su consumo local.

\section{UNA DÉCADA CRÍTICA (1933-1941)}

Para 1930 se produjo la crisis mundial que provocó una merma en el nivel de crecimiento de la economía. Las condiciones externas variaron dramáticamente por la caída de volúmenes y precios de productos comerciados, en particular de los agropecuarios. Esta caída no se verificó para las manufacturas locales, que se vieron beneficiadas por la devaluación de la moneda, el aumento de aranceles y restricciones diversas a la importación (Nogués, 2011). De las tres empresas analizadas Bunge y Born fue la que mejor reaccionó a las nuevas condiciones, intensificando sus actividades industriales. En 1932 automatizó su productora de envases Centenera y amplió la capacidad de Grafa para elaborar textiles de algodón. En 1936 Alba inauguraría una nueva planta de fabricación de pinturas, y en 1937 fundaría Compañía Química, que comenzó a elaborar ácido sulfúrico y fertilizante. A su vez, Molinos Río de la Plata abría nuevas plantas de fabricación de aceite en el interior argentino en 1937 y 1938.

Garovaglio y Zorraquín también inició su diversificación adquiriendo algunos establecimientos ganaderos obtenidos a bajo precio por la crisis, e invirtiendo en algunos bancos regionales. La escasa atención a la industria era fruto de la concepción de Pico Zorraquín, quien no deseaba diversi-

${ }^{20} \mathrm{El}$ problema del embolsado de los granos surgió ya a fines del siglo XIX, con diferentes iniciativas y protección estatal. 


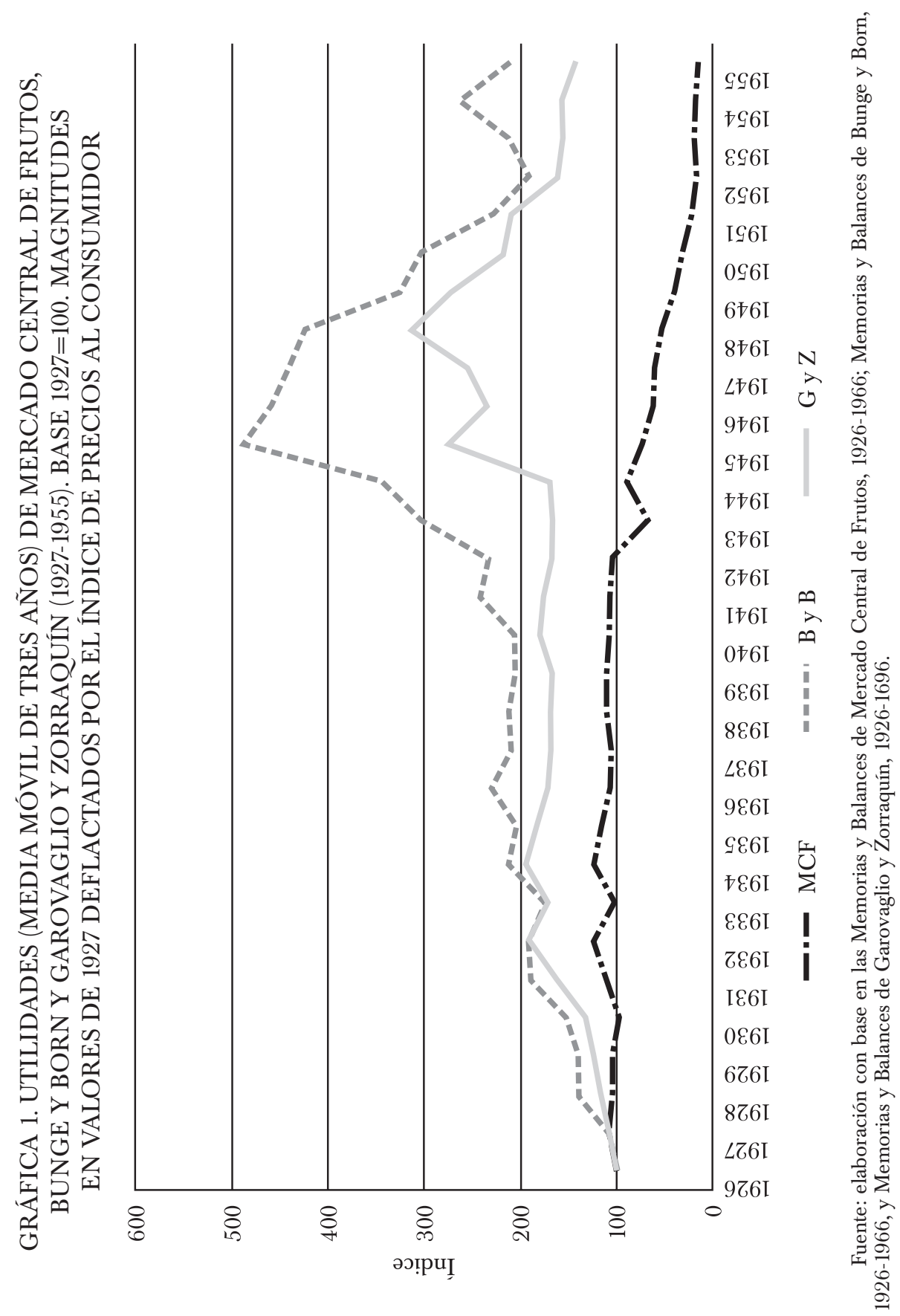


ficar su empresa hacia destinos manufactureros, un tema que generaría tensiones con su futuro sucesor, su hijo Fred (Zorraquín, Memorias, s. a.). El presidente de Mercado Central de Frutos, Alberto Hueyo, tampoco concibió en esos años la diversificación como una oportunidad, aunque podría haber utilizado para ese objeto espacio no ocupado del gigantesco edificio. Por ello Mercado Central de Frutos continuó con sus actividades tradicionales de comercialización de lanas y frutos, tomando más relevancia la demanda de las fábricas textiles locales. Algunas de ellas, como SoulasCampomar, estaban ubicadas en zonas cercanas a sus instalaciones. De acuerdo con la Memoria y Balance de Mercado Central de Frutos de 1933, como un modo de adaptarse a los tiempos, ya desde 1932 comenzaría a realizar remates de lanas en sus instalaciones, con el objetivo de brindar un servicio adicional a sus clientes.

El efecto general de la crisis sobre las utilidades de las empresas fue bajar su magnitud, aunque sin tornarlas negativas en ningún año. Durante el periodo de 1933 a 1941 Bunge y Born fue la menos perjudicada por la caída de la actividad, presentando un promedio de $8 \%$ de utilidades, mientras que la cifra fue de 5\% para Garovaglio y Zorraquín y Mercado Central de Frutos (véase cuadro 1). En Bunge y Born comenzaban a ser relevantes los fondos aportados por las empresas controladas. En 1932 los dividendos de estas representaban $11 \%$ de las ganancias totales. De todas maneras para el grupo entre 1933 y 1941 las utilidades agregadas, de 8\%, eran superiores a las brindadas por sus empresas manufactureras (Molinos, Grafa, C. Química y Alba) de 4.7\%. ${ }^{21}$ Todavía seguía siendo más rentable la intermediación de granos.

Los datos al interior del grupo Garovaglio y Zorraquín para 1942 muestran que su estrategia de diversificación hacia el sector primario y servicios había reducido la rentabilidad media ofrecida por su actividad tradicional: la ganadería rendía 5.5\% sobre los fondos que absorbía, los títulos y acciones 6.5\%, mientras que el área financiera (muy vinculada a su intermediación azucarera) lograba $10 \%$ de retorno. ${ }^{22}$ Las inversiones en la industria eran una oportunidad que el grupo Garovaglio y Zorraquín aún no había intentado.

${ }^{21}$ Cálculo según los datos de los balances de estas empresas incluidos en la revista Veritas (1933-1942).

${ }^{22}$ Acta del Directorio Garovaglio y Zorraquín (6 de abril de 1942). 


\section{EL CRECIMIENTO MANUFACTURERO (1942-1948)}

La segunda guerra mundial ofreció un contexto favorable para la industria local, dada las limitaciones de los países beligerantes en producir excedentes para la exportación. Las empresas argentinas en ese lapso no sólo sustituyeron las importaciones, sino que también proveyeron de productos a otros países americanos. Garovaglio y Zorraquín inició una exportación de aceite y azúcar en 1939 que impactó favorablemente en sus utilidades. ${ }^{23}$ Por su parte Mercado Central de Frutos se benefició por un aumento en la demanda de lana, lo que se vio reflejado tanto en los precios como en el uso de sus instalaciones. Bunge y Born incrementó notablemente sus ventas de granos en 1940, aunque luego su volumen caería. Según Green y Laurent (1988, p. 203), al mismo tiempo aumentó su rentabilidad industrial. ${ }^{24}$ Entre 1942 y 1948 las utilidades de Bunge y Born presentan un promedio anual de 15\%, mientras que la magnitud para Mercado Central de Frutos fue de $8 \%$ y para Garovaglio y Zorraquín, de 12\%. Estos niveles eran similares a los logrados en la década de 1920 (véase cuadro 1).

Con el golpe militar de 1943 y el posterior advenimiento del gobierno peronista (1946-1955) se produjeron fuertes cambios en la política económica, al alentarse la producción industrial mediante un fuerte proteccionismo y crédito subsidiado. Nuevas medidas afectaron gravemente la comercialización de productos agropecuarios, a la vez que aumentó la presión impositiva sobre el campo. La nacionalización de los depósitos bancarios implicó una dificultad creciente para las consignatarias a la hora de obtener fondos para adelantar a sus clientes, actividad que había sido una muy importante fuente de ingresos. En el caso de Garovaglio y Zorraquín, al establecerse precios máximos bajos y limitarse las comisiones que podía cobrar, se afectó gravemente su rentabilidad. Ello implicó que para 1948 la intermediación azucarera sólo aportara $11 \%$ de los beneficios del grupo. ${ }^{25}$

Una de las mayores expresiones de intervención estatal en la economía durante el periodo peronista fue el Instituto Argentino para la Promoción del Intercambio. Si bien continuaba en cierta forma con las políticas estatales de la década de 1930, este organismo tomó la gestión del comercio exterior argentino, teniendo como uno de sus objetivos controlar el ingreso y salida de divisas, al mismo tiempo que intervenía en el mercado agropecuario comprando la producción de manera directa y controlando los precios. Los resultados de dicho accionar aún son discutidos. ${ }^{26} \mathrm{Al}$ mo-

\footnotetext{
${ }^{23}$ Acta del Directorio Garovaglio y Zorraquín (18 de octubre de 1941).

${ }^{24}$ Para 1942, según las Memorias y Balances de Bunge y Born (1942), 13\% de las utilidades de Bunge y Born se originaban en los dividendos de empresas industriales.

${ }^{25}$ Borrador de Balance de Garovaglio y Zorraquín Sociedad Anónima, 30 de junio de 1948.

${ }^{26}$ Por ejemplo, véase Sourrouille y Ramos (2013).
} 
nopolizar el comercio exterior desplazó a las empresas privadas de comercialización y exportación, como Bunge y Born, y Garovaglio y Zorraquín. ${ }^{27}$

La intervención del Instituto Argentino para la Promoción del Intercambio también afectó, en menor medida, Mercado Central de Frutos. Si bien el negocio central era cobrar por el depósito de mercaderías, los consignatarios ya no tenían la capacidad para manejar los precios ni la de exportar directamente. Aun así, continuó con sus operaciones, adaptándose a la situación. ${ }^{28}$ Mercado Central de Frutos sufriría en mayor medida las medidas salariales y fiscales del peronismo (Cuesta, 2014).

Las nuevas políticas económicas modificaron sustancialmente las condiciones macroeconómicas. El sector industrial, dada su centralidad en el proyecto económico, recibió un conjunto de beneficios, desde subsidios y promociones fiscales, hasta créditos con tasa de interés negativa y preferencias cambiarias para la importación de equipamiento. Por otro lado, el control de la política monetaria, con la nacionalización de los depósitos y la expansión de las atribuciones del Banco Central, alteró el flujo del crédito, dando preferencia a ciertos sectores. Los acopiadores y comercializadores agropecuarios vieron disminuir su capacidad financiera. ${ }^{29}$ Los mercados de capitales, aun con los incentivos de la política económica, no lograron funcionar adecuadamente (véase Rougier, 2012b).

La actividad principal de Bunge y Born hasta ese momento, la comercialización de granos, fue muy afectada durante el peronismo. En 1945 se expropiaron sus elevadores de granos y en 1946 se estableció el ya mencionado Instituto Argentino para la Promoción del Intercambio. Bunge y Born pudo continuar en el rubro a un nivel más reducido trabajando para el organismo público, lo que le permitió mantener alguna rentabilidad en la actividad (véase gráfica 2). ${ }^{30}$ De todas maneras, sus ventas al exterior entre 1947 y 1955 se redujeron en promedio a una cuarta parte de lo que habían sido entre 1939 y 1946 (Green y Lauren, 1988). ${ }^{31}$ Por otra parte desaparecieron las rentables actividades financieras de adelanto de fondos, al

${ }^{27}$ A partir de la creación del Instituto Argentino para la Promoción del Intercambio, las firmas que hasta entonces operaban en el comercio exterior no dejaron la actividad, sino que pasaron a operar por cuenta y orden de este organismo.

${ }^{28}$ El Plan Quinquenal y el Mercado Central de Frutos (14 de abril de 1953). Diario Democracia, p. 5.

${ }^{29}$ Este problema es planteado en Zorraquín, Memorias

${ }^{30}$ Según Jorge Born, por la inoperancia del Instituto Argentino para la Promoción del Intercambio en sus actividades, se terminó contratando a Bunge y Born para las actividades de exportación, lo que le permitiría hacer una "buena diferencia" a la empresa en esas operaciones. Véase Born (2008), también Martínez de Hoz (1967).

${ }^{31}$ La retórica política del peronismo fustigó duramente las actividades de Bunge y Born en la comercialización de productos agrícolas, dando una imagen emblemática a la empresa. Aunque no fue el único caso, ya que otros grupos estuvieron en la mira del gobierno, como el grupo Bemberg en Belini (2008). Para observar la compleja relación entre el peronismo y las empresas, véase 


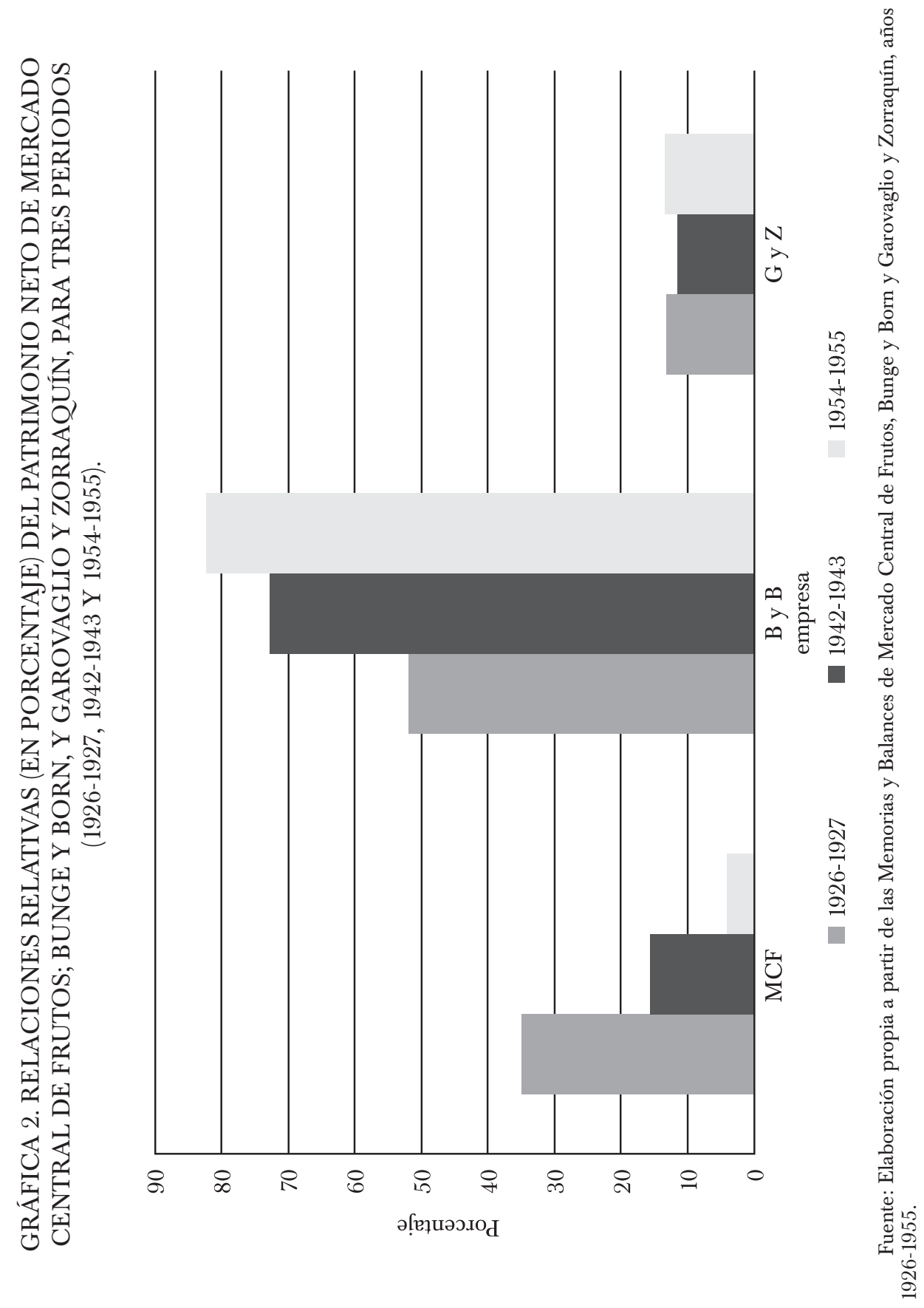


alterarse sus relaciones con los productores y no contar con financiamiento bancario. Al tiempo que se reducía su actividad como intermediario, Bunge y Born continuó con sus políticas de expansión industrial. En 1948 Compañía Química inauguró una nueva planta en Llavallol para insumos destinados a la ganadería, y se asoció con otra firma para generar Sulfacid, una empresa que puso en marcha una planta de ácido sulfúrico en 1950 en Santa Fe. Entre 1949 y 1951 Grafa amplió su capacidad mediante la incorporación de husos y telares. El incremento de la importancia de la industria se reflejó en el origen de las utilidades del grupo: entre 1948 y 1955 los dividendos de sus empresas manufactureras aportaron 68\% de los beneficios totales (Memorias y Balances de Bunge y Born, 1948-1955). Este fue un cambio importante, ya que antes de 1945 esta proporción no superaba 15 por ciento.

Mercado Central de Frutos también sufrió los efectos de las políticas económicas peronistas. En las memorias y balances del periodo, su directorio hacía notar de manera constante que el aumento de los salarios y los impuestos superaba ampliamente al crecimiento de sus ingresos. Además de la política salarial y fiscal, el retraso en el tipo de cambio afectó a la exportación de lanas, producto central en los depósitos de Mercado Central de Frutos.

La diversificación relativamente tardía de Garovaglio y Zorraquín hacia actividades industriales fue fruto de la paulatina toma del control, a lo largo de la década de 1940, del holding por Fred Zorraquín. Este presentaba un carácter muy distinto a su conservador padre; audaz e impulsivo, le apasionaba iniciar nuevos negocios (Zorraquín, Memorias, p. 31). Fred Zorraquín reaccionó rápidamente a las nuevas condiciones imperantes redireccionando recursos hacía inversiones industriales. Así, Garovaglio y Zorraquín adquirió participación en plantas productoras de máquinas herramientas y de tambores de acero, laminadoras de hierro y bolsas arpilleras. Para 1948 las empresas manufactureras absorbían 31\% de las inversiones del grupo. La firma también actuó con éxito en la importación de herramientas y maquinaria industrial, en gran demanda por el crecimiento de los establecimientos manufactureros. Esta importación era favorecida por la asignación racionada de divisas.

Las políticas industrialistas del periodo beneficiaron a las dos empresas que se diversificaron hacia la industria: Bunge y Born, y Garovaglio y Zorraquín. Mercado Central de Frutos, que continuó operando fundamentalmente en relación con el comercio exterior, sufrió una merma conside-

Belini (2014) y Rougier (2012a, 2012b). Un caso interesante es el de la empresa SIAM, en Cochran y Reina (2011), Rougier (2008) y Rougier y Schvarzer (2006). 
rable en sus utilidades, tanto por el estancamiento de los precios de sus productos, como por los aumentos impositivos y salariales.

\section{LA DESACELERACIÓN: 1949-1955}

Como consecuencia de la crisis de los años 1949 y 1951, las políticas económicas del peronismo fueron revisadas. Se tomaron medidas con el objetivo de resolver los problemas de la alta inflación, el déficit en el comercio exterior y en las cuentas públicas. Se llevó adelante cierta restricción al crédito y una modificación en las políticas destinadas al sector agropecuario. El resultado fue una baja significativa de la tasa de inflación, que se redujo a un dígito durante los años 1954-1955, y una merma del crecimiento. Las modificaciones en las políticas económicas impactaron en las tres empresas analizadas. La rentabilidad de Bunge y Born se mantuvo alta, pero en un menor nivel (11\%), al tiempo que se produjo una mínima reducción en su patrimonio. Un panorama similar se observa para esos años en los indicadores de Garovaglio y Zorraquín, que presentó la misma tasa de ganancias que Bunge y Born (véase cuadro 2).

La caída en la rentabilidad de Mercado Central de Frutos fue más aguda por su magnitud. La antigüedad de las instalaciones y la falta de renovación hicieron que se redujera dramáticamente el valor de sus activos. Para satisfacer a los accionistas descontentos, en 1950 se procedió a vender parte de los terrenos, como un modo de aumentar los ingresos e incrementar los dividendos. Sin embargo, esta medida excepcional se reflejó sólo en ese año, permaneciendo las utilidades muy por debajo de las obtenidas en las décadas previas. Sólo en 1951 el gobierno modificó el tipo de cambio para la exportación de lanas, con lo cual hubo cierto aumento en el ingreso de estos productos al mercado.

El estancamiento patrimonial observado tanto en Garovaglio y Zorraquín como en Bunge y Born a lo largo de los años 1949-1955 puede haber sido en parte resultado de una pérdida paulatina de las ventajas de grandes empresas respecto de entidades más pequeñas. Es posible que grandes grupos o empresas se expandieran más rápidamente que el resto del sector industrial en la primera mitad de la década de 1940, al contar con mayores facilidades en la obtención de divisas racionadas para la adquisición de insumos y equipamiento importado. En ese lapso los aumentos en los costos laborales producidos por los cambios en la legislación fueron fácilmente absorbidos por las altas ganancias. Cuando la situación macroeconómica se estancó, luego de 1948, la presión de los costos laborales se hizo más significativa para grandes empresas, que eran fácilmente controladas por los organismos fiscalizadores, además de contar con sindicatos activos y 
CUADRO 2. PATRIMONIO NETO DE MERCADO CENTRAL DE FRUTOS; BUNGE Y BORN, Y GAROVAGLIO Y ZORRAQUÍN (1926-1955). BASE $1926=100$. VALORES ORIGINALES DEFLACTADOS POR EL ÍNDICE DE PRECIOS AL CONSUMIDOR

\begin{tabular}{lccc}
\hline & Bunge y Born & Garovaglio y Zorraquín & Mercado Central de Frutos \\
1926 & 100 & 100 & 100 \\
1933 & 175 & 170 & 104 \\
1942 & 233 & 167 & 104 \\
1949 & 329 & 168 & 56 \\
1955 & 313 & 167 & 32 \\
\hline
\end{tabular}

Fuentes: elaboración propia a partir de Memorias y Balances de Mercado Central de Frutos, Bunge y Born y Garovaglio y Zorraquín, años 1926 a 1955.

organizados. Al mismo tiempo, las empresas más pequeñas, con desventajas en equipamiento y organización, tendrían la ventaja de presentar una mayor evasión e incumplimiento impositivo (por ejemplo en el pago de cargas sociales) y menor observancia de las normas de seguridad e higiene, debido al menor peso sindical. ${ }^{32}$

La crisis económica de 1949-1951 impactó en las tres empresas. El retraso cambiario redujo la operatoria en Mercado Central de Frutos, ya que el precio de las lanas llevó a una caída en las exportaciones del producto. La relativa austeridad monetaria y crediticia del gobierno entre 1949 y 1955 redujo en parte el financiamiento a algunas de las actividades de Bunge y Born, y de Garovaglio y Zorraquín, con lo cual las utilidades cayeron con respecto al periodo anterior.

\section{CONSIDERACIONES FINALES}

A lo largo de este trabajo se analizaron indicadores patrimoniales y económicos de tres empresas argentinas entre 1926 y 1955. Las firmas eran representativas de sectores importantes de la economía argentina de fines del siglo XIX y gran parte del XX. Bunge y Born se inició como comercializadora de granos (tanto a nivel local como para exportación) y se diversificó

${ }^{32}$ Sobre este tema véase Goetz (1976). Este autor encuentra que a partir de la posguerra se produjo un proceso de debilitamiento de grandes empresas respecto a entidades de menor dimensión. 
hacia rubros industriales desde principios de siglo. Mercado Central de Frutos nació, creció y cerró como espacio de concentración y comercialización de lanas y cueros para la exportación. La tercera organización, Garovaglio y Zorraquín, se dedicó a actividades de importación y distribución de azúcar, diversificándose luego hacia actividades ganaderas y bancarias durante la Gran Depresión.

En la década de 1920 se observa un buen desempeño de las tres empresas, en pleno apogeo de la Argentina próspera. Con la Gran Depresión se produjo una caída de las utilidades de las tres firmas y en particular de Mercado Central de Frutos, y de Garovaglio y Zorraquín. Bunge y Born, que había comenzado su diversificación con anterioridad, sufrió una reducción menor en sus beneficios. Iniciada la segunda guerra mundial aumentaron las utilidades de las tres firmas, con un desempeño excepcional de Bunge y Born gracias a sus fábricas. Durante el gobierno peronista, Garovaglio y Zorraquín viró sus esfuerzos hacia la producción manufacturera e importación de equipamiento. Al mismo tiempo Mercado Central de Frutos vio reducidas sus utilidades por la regulación impuesta sobre la comercialización de lana, junto con los aumentos en los costos salariales e impositivos. Paralelamente se reducía su área de influencia por la migración de los lanares al sur del país. En la segunda etapa peronista se observan diferencias en los indicadores de las tres empresas analizadas. Tanto Bunge y Born como Garovaglio y Zorraquín sufrieron un descenso de su rentabilidad, aunque continuaron con altos beneficios. El patrimonio de estas dos firmas se estancó; en el caso de Mercado Central de Frutos se produjo una fuerte caída en sus activos.

Inmersas en la misma economía, distintas estrategias produjeron resultados diversos en cada una de las firmas analizadas. Una diversificación temprana hacia la industria, junto con la integración de sus actividades comerciales y manufactureras fue la clave del éxito de Bunge y Born, que triplicó el valor de sus recursos propios entre 1926 y 1955 (véase cuadro 2). Este éxito es señalado en uno de los estudios clásicos dedicados al grupo (Green y Laurent, 1988) que reconoce a Bunge y Born como uno de los pioneros del desarrollo industrial con tecnología de avanzada en Argentina, contribuyendo a que el país no fuera meramente un exportador de materias primas. ${ }^{33}$ Garovaglio y Zorraquín, por su parte, intentó primero una diversificación poco rentable hacia el agro y bancos, para ingresar más tarde a los sectores de mayor dinamismo bajo el peronismo. El resultado fue el mantenimiento del nivel alcanzado a principios de la década de

${ }^{33}$ Schvarzer (1989, p. 66) en su obra también clásica sobre Bunge y Born tuvo como tema principal su diversificación, aunque consideró que su éxito se debió más a un comportamiento oligopólico en los diversos sectores en que actuaba, que a una correcta estrategia de largo plazo. 
1930, sin superarlo. Entre 1926 y 1955 su valor patrimonial aumentó 67\%. El caso de Mercado Central de Frutos muestra la fragilidad de la no adaptación a los cambios estructurales. Aunque mantuvo su patrimonio hasta los años de la segunda guerra mundial, paulatinamente fue reduciendo sus actividades, hasta extinguirse en 1963.

Un análisis reciente de la relación entre desarrollo empresarial y diversificación avala estas conclusiones, señalando que cuando existen entornos inestables sin mercados de capitales bien desarrollados, es más probable que la diversificación sea exitosa si se realiza hacia actividades relacionadas (Erdorf, Hartmann-Wendels, Heinrichs, Mantz, 2013). El desempeño comparativo de las compañías analizadas se encuadran bien en este marco, un resultado que es también compatible con las conclusiones a las que se llega con respecto a otras firmas de América Latina, como es el caso en Brasil de Itaú (Fernández y Casanova, 2012) y Gerdau (Lannes, 2015), que combinaron diversificación relacionada con la internacionalización de las organizaciones. En el caso de Itaú, su expansión incorporó la banca comercial, minorista y mayorista, y luego de inversión e internacional. El Grupo Gerdau fue una empresa familiar típica, que partiendo de una fábrica de clavos a inicios del siglo xx llegó a ser una de las empresas metalúrgicas más importantes del mundo. Una situación algo diferente puede observarse en la evolución de Sadía, con su diversificación relacionada combinada a una integración a un grupo mayor (Dalla, 2002). En los estudios sobre empresas mexicanas abundan los ejemplos de conductas diversas en las decisiones y procesos de diversificación o integración, como los de Zambrano o Slim (Cerutti, 2015; Marichal y Cerutti, 1997). Los casos trabajados por Dávila para Colombia ilustran el efecto de las diversificaciones relacionadas (2011). Las empresas chilenas han mostrado diversificación integrada en muchos casos, según Martínez (2015). ${ }^{34}$

El análisis realizado ha permitido observar el desempeño, estrategias empresariales y adaptación al contexto limitado a tres empresas. Un desafío para estudios futuros será analizar si la clave del desempeño fue la diversificación relacionada, o simplemente el giro hacia las actividades industriales en un contexto favorable. Por otra parte, son necesarias investigaciones sobre rentabilidad en el largo plazo, extendidos tanto hacia las primeras décadas del siglo (donde la información es más escasa), o bien hacia la segunda mitad del siglo Xx, cuando el análisis contable se vuelve sumamente complejo por el impacto de la inflación. Queda, por lo tanto, en la agenda la aspiración de construir series de mayor amplitud temporal,

\footnotetext{
${ }^{34}$ Para un enfoque general del tema, y perspectivas de caso en Latinoamérica, véase Fernández y Lluch (2015). Con casos centroamericanos como Honduras véase Discua, Ramos, Raudales, Fortín (2015) y para Costa Rica, Leiva (2015).
} 
así como aumentar la muestra para poder contrastar la rentabilidad por tipos de empresas o sectores. Finalmente la comparación con series similares de Latinoamérica y de otras regiones del mundo permitirá conocer mejor cuán específico ha sido el desempeño de estas empresas argentinas.

\section{LISTA DE REFERENCIAS}

Azzi, M. S. y TitTo, R. DE (2008). Bunge \& Born (pp. 169-188). En M. S. AzzI, y R. DE Tiтto, Pioneros de la industria argentina. Buenos Aires: El Ateneo.

BARbERO, M. I. (2000). Mercados, redes sociales y estrategias empresariales en los orígenes de los grupos económicos. De la Compañía General de Fósforos al Grupo Fabril, 1889-1929. Estudios Migratorios Latinoamericanos, 44, 119-146.

BARbero, M. I. (2006). La historia de empresas en Argentina: trayectoria y temas de debate en las últimas dos décadas (pp. 153-172). En J. Gelman (coord.), La historia económica argentina en la encrucijada. Balances y perspectivas. Buenos Aires: Prometeo.

BARbero, M. I. y JACOB, F. (eds.) (2008). La nueva historia de empresas en América Latina y España. Buenos Aires: Temas.

BARbero, M. I. y LLUCH, A. (2015). El capitalismo familiar en Argentina: modelos y dinámicas en el largo plazo (pp. 219-260). En P. Fernández y A. LluCH (eds.), Familias empresarias y grandes empresas familiares en América Latina y España. Una visión de largo plazo. Bilbao: Fundación BBvA.

BeLini, C. (2008). Monopolios, poder y política. Perón contra el grupo Bemberg, 19481959. Secuencia. Revista de Historia y Ciencias Sociales, 72, 101-128.

BELINI, C. (2014). Convenciendo al capital. Peronismo, burocracia, empresarios y política industrial, 1943-1955. Buenos Aires: Edhasa.

Bonilla, C., Sepúlveda, J. y Carvajal, M. (2010). Family ownership and firm performance in Chile: A note on Martinez et al.'s evidence. Family Business Revierw, 23(2), 148-154.

BORN, J. (2008). Creating emerging markets. Entrevista realizada por Andrea Lluch. Enhttp://www.hbs.edu/businesshistory/Documents/emerging-markets-transcripts/ Born_Jorge_Web.pdf

CASSIS, Y. y BRAUTASET, C. (2003). The performance of European business in the twentieth century: A pilot study. Business and Economic History on line, vol. 1. http://www. thebhc.org/sites/default/files/Cassisbrautaset_0.pdf.

Cerutti, M. (2015). Grandes empresas y familias empresariales en México (pp. 153188). En P. Fernández y A. LluCh (eds.), Familias empresarias y grandes empresas familiares en América latina y España. Una visión de largo plazo. Bilbao: Fundación BBVA.

Ceva, M. (2010). De la exportación cerealera a la diversificación industrial. Las empresas Bunge y Born en Argentina (1884-1940). Estudios Migratorios Latinoamericanos, pp. 81-98. 
Cochran, T. y Reina, R. (2011). Torcuato Di Tella y Siam. Espiritu de empresa en la Argentina (Estudio complementario de Marcelo Rougier). Buenos Aires: Lenguaje Claro. (La edición original fue: Entrepreneurship in Argentine culture; Torcuato Di Tella and S.I.A.M, Philadelphia, 1962.)

Cuesta, E. M. (2013). Precios, salarios, peronismo y empresa. El caso del Mercado Central de Frutos de Argentina (1938-1958). Anuario del Centro de Estudios Económicos de la Empresa y el Desarrollo, 5, 53-80.

Cuesta, E. M. (2014). Precios, salarios y empresa en la Argentina próspera. El caso del Mercado Central de Frutos (1887-1930). H-Industri@, 8(14), 121-152.

Dalla, A. J. (2002). Sadia, Perdigão e Hermes Macedo: nascimento, expansão e crise por ocasião da passagem do poder nas empresas familiares (pp. 153- 170). En A. M. Kirschner, E. Rodrigues y P. CAPELLIN (orgs.), Empresa, empresários e globalização. Río de Janeiro: Relume Dumará.

DÁvila, C. (2011). Empresarios, diversificación de inversiones y nexos con la propiedad territorial en cinco regiones colombianas, 1880-1930. Revista de Historia de la Economía y de la Empresa, 5, 89-116.

Discua, A., Ramos, C., Raudales, C. y Fortín, L. (2015). Las grandes empresas familiares en Honduras: influencia de la intervención del Estado y la inmigración en el siglo Xx (pp. 219-343). En P. FERnÁNDEZ y A. LluCH (eds.), Familias empresarias y grandes empresas familiares en América Latina y España. Una visión de largo plazo. Bilbao: Fundación BBVA.

Erdorf, S., Hartmann-Wendels, Th., Heinrichs, N., Matz, M. (2013). Corporate diversification and firm value: A survey of recent literature. Financial Markets and Portfolio Management, 27(2), 187-215.

FAnelli, J. M. y Albrieu, R. (2011). Fluctuaciones macroeconómicas y crecimiento en Argentina: una visión de largo plazo (pp. 43-81). En AA. VV., La Argentina del largo plazo: crecimiento, fluctuaciones y cambio estructural. Buenos Aires: Programa de Naciones Unidas para el Desarrollo.

Fernández, P. y Casanova, L. (2012). Algunas claves de la longevidad de las grandes empresas familiares brasileñas. Apuntes, 39(70), 273-300.

FERnÁndez, P. y LluCH, A. (eds.) (2015). Familias empresarias y grandes empresas familiares en América Latina y España. Una visión de largo plazo. Bilbao: Fundación BBVA.

Goetz, A. L. (1976). Concentración y desconcentración en la industria argentina desde la década de 1930 a la de 1960. Desarrollo Económico, 60, 507-548.

Gourvish, T. (2006). What can business history tell us about business performance? Competition and Change, 10(4), 375-392.

Green, R. H. y Laurent, C. (1988). El poder de Bunge y Born. Buenos Aires: Legasa.

GutiérRez, L. y Korol, J. C. (1988). Historia de empresas y crecimiento industrial en la Argentina. El caso de la Fábrica Argentina de Alpargatas. Desarrollo Económico, 28(111), 401-424.

Guy, D. J. (1988). Refinería Argentina, 1888-1930: límites de la tecnología azucarera en una economía periférica. Desarrollo Económico, 28(111), 353-373. 
Haber, S. (1992). Business enterprise and the great depression in Brazil: A study of profits and losses in textile manufacturing. The Business History Review, 66(2), 335-363.

LANCIOTTI, N. S. (2011). Inversión británica y redes empresariales: la estructura organizativa y las estrategias de gestión del grupo River Plate Trust, Loan \& Agency en Argentina, 1881-1962. Anuario del Centro de Estudios Económicos de la Empresa y el Desarrollo, 3, 85-126.

LANCIOTTI, N. S. y BARTOLOMÉ, I. (2014). Global strategies, differing experiences. Electricity companies in two late-industrialising countries: Spain and Argentina, 18901950. Business History, 56(5), 724-745.

LANNES, J. (2015). Grupo Gerdau: la construcción de un competidor global. Apuntes, 41(75), 141-169.

Leiva, J. C. y Guillén, E. (2015). De un escenario dominado por una élite de familias a uno disperso con presencia de múltiples protagonistas. El capitalismo en Costa Rica durante el siglo Xx (pp. 293-317). En P. Fernández y A. Lluch (eds.), Familias empresarias y grandes empresas familiares en América latina y España. Una visión de largo plazo. Bilbao: Fundación BBVA.

LLACH, J. (1984). El plan pinedo de 1940, su significado histórico y los orígenes de la economía política del peronismo. Desarrollo Económico, 23(92), 515-558.

LÓPEZ, A. (2006). Empresas, instituciones y desarrollo económico: un análisis general con reflexiones para el caso argentino. Boletín Informativo Techint, 320, 33-72.

Marichal, C. y Cerutti, M. (comps.) (1997). Historia de las grandes empresas en México, 1850-1930. México: Universidad Autónoma de Nuevo León.

Martínez, J., StÖHr, B. y Quiroga, B. (2007). Family ownership and firm performance: Evidence from public companies in Chile. Family Business Reviere, 20(2), 83-94.

Martínez, J. (2015). Grandes familias empresarias en Chile. Sus características y aportes al país (1830-2012) (pp. 409-436). En P. FERnÁndEZ y A. LluCH (eds.), Familias empresarias y grandes empresas familiares en América Latina y España. Una visión de largo plazo. Bilbao: Fundación BBVA.

MARTínez DE HOZ, J. (h.) (1967). La agricultura y la ganadería argentina en el periodo 19301960. Buenos Aires: Editorial Sudamericana.

Monsalve, M. (2015). Evolución de la gran empresa familiar peruana 1890-2012 (pp. 381-407). En P. Fernández y A. LluCH (eds.), Familias empresarias y grandes empresas familiares en América Latina y España. Una visión de largo plazo. Bilbao: Fundación BBVA.

Newland, C. (2012). Mercado Mammoth: infraestructura y comercio agropecuario en Buenos Aires (1887-1916). Revista de Instituciones, Ideas y Mercados, 56, 109-130.

Newland, C. (2015). Sobre las estrategias, utilidades y valuación del grupo Garovaglio y Zorraquín durante el siglo Xx. Revista de Historia Industrial, 60, 81-102.

Nogués, J. (2011). Agro e industria: del centenario al bicentenario. Buenos Aires: Hispania Libros. 
Petrei, H. (1973). Rates of return to physical capital in manufacturing industries in Argentina. Oxford Economic Papers, 25(3), 378-404.

PInEDA, Y. (2007). Manufacturing profits and strategies in argentine industrial development, 1904-1930. Business History, 49(2), 186-210.

Rougier, M. (2008). Industria y peronismo: la fábrica de tubos de SIAM Di Tella S. A. (1948-1955). Estudios Ibero Americanos, 34, 76-97.

Rougier, M. (2009). La expansión por defecto del Estado empresario. La política económica frente a la crisis de las empresas industriales en la Argentina, 1960-1976. Investigaciones de Historia Económica, 5(15), 75-108.

Rougier, M. (2012a). La economía peronista. Una perspectiva histórica. Buenos Aires: Sudamericana.

Rougier, M. (2012b). El mercado de valores durante el peronismo. Las dificultades para conformar un ámbito de capitalización empresaria (1944-1955). Investigaciones y Ensayos, 59, 511-564.

Rougier, M. (2013). Reflexiones sobre la historia de la industria y las empresas en América Latina. Revista de Historia Industrial, 53, 13-24.

Rougier, M. y SchVArzer, J. (2006). Las grandes empresas no mueren de pie: el (o)caso de SIAM. Buenos Aires: Grupo Editorial Norma.

SÁbato, J. (1991). La clase dominante en la Argentina moderna. Formación y características. Buenos Aires: Imago Mundi.

SAntARCÁngelo, J. E. (2012). Concentración, rentabilidad y extranjerización en Argentina. Una mirada desde la cúpula empresaria. Ensayos de Economía, 22(40), 39-59.

SCHVARZER, J. (1989). Bunge Ë Born: crecimiento y diversificación de un grupo económico. Buenos Aires: Centro de Investigaciones Sociales sobre el Estado y la Administración. Recuperado de http://www.jorgeschvarzer.com.ar/info/pdf_web/198ae 9/ bunge-born.pdf.

Sourrouille, J. y Ramos, A. (2013). El trigo y las ganancias del iAPI entre 1946 y 1949: Miranda y la política económica en los inicios del peronismo. Desarrollo Económico, 53(209), 27-56.

TAFUnELL, X. (2000). La rentabilidad financiera de la empresa española, 1880-1981: una estimación en perspectiva sectorial. Revista de Historia Industrial, 18, 71-112.

YukL, G. y MAHsud, R. (2010). Why flexible and adaptive leadership is essential? Consulting Psychology Journal: Practice and Research, 62(2), 81-93.

\section{Archivos}

Acta del Directorio de Garovaglio y Zorraquín, 18 de octubre de 1941. Archivo Garovaglio y Zorraquín Sociedad Anónima.

Archivo de la Biblioteca Tornquist del Banco Central de la República Argentina. 
Borrador de Balance de Garovaglio y Zorraquín Sociedad Anónima, 30 de junio de 1948. Archivo Garovaglio y Zorraquín Sociedad Anónima.

Memorias y Balances de Bunge y Born Sociedad Anónima (1926-1966). Archivo Fundación Bunge \& Born.

Memorias y Balances de Garovaglio y Zorraquín Sociedad Anónima, (1926-1966). Archivo Garovaglio y Zorraquín Sociedad Anónima.

Memorias y Balances de Mercado Central de Frutos Sociedad Anónima. En Boletín de la Bolsa de Comercio de Buenos Aires (1926 a 1966). Archivo de la Bolsa de Comercio de Buenos Aires.

Zorraquín Nougués, Federico, Memorias, s. a., s. 1. Archivo Garovaglio y Zorraquín Sociedad Anónima.

\section{Hemerografía}

El Avisador Mercantil, Buenos Aires, Argentina.

Diario Democracia, Buenos Aires, Argentina. 